\title{
Analysis of Science and Engineering Graduates Employment Ability Factors based on FAHP
}

\author{
Liwei $\mathrm{Gu}^{1}$, Yubin Wang ${ }^{2}$ and Yuhong Zhang ${ }^{3}$ \\ ${ }^{1}$ College of Education, Hebei Normal University of Science\& Technology \\ Qinhuangdao, Hebei, 066004, China, \\ ${ }^{2}$ College of Math and Information Science \& Technology, Hebei Normal University of \\ Science\& Technology \\ Qinhuangdao, Hebei, 066004, China, \\ ${ }^{3}$ College of Education, Hebei Normal University of Science \& Technology \\ Qinhuangdao, Hebei, 066004, China, \\ 1'gu.liwei@163.com, ${ }^{2}$ qhdwyb@126.com, ${ }^{3} 13933690306 @ 163 . c o m$,
}

\begin{abstract}
While employment ability is part of the core factors affecting the employment of College students, science and engineering graduates employment has its own specialty, social demands, and it has many differences between other subjects. In hope of playing a promoting role on the using of employment ability theory, this paper use FAHP method to data mining the data of science and engineering employment, and obtained the employment ability factors model of students of science and engineering. Compares to other subjects, this article pays greater attention to use computer software to reduce the mathematical method complexity, and then get the science and engineering graduates' employment ability model.
\end{abstract}

Keywords: Employment ability, Science and Engineering Graduates, FAHP, data mining

\section{Introduction}

In recent years, the employment of college students has become a prominent communal problem. According to "The annual Chinese college students' Employment Statistics Report" which was written by MYCOS institute, the 2007 - 2010 employment rates were around $80 \%$ (including a number of liters of scholars) [1]. While the 2012 employment rate of graduates more than 2011 , increased by $0.6 \%$, reached $90.2 \%$, but $14 \%$ in the low employment status, which meanings engaged in the incoherent and professional work and in the group of local minimum monthly income of $1 / 4$. There are $89.6 \%$ graduates, in low employment status, for cannot find the relevant professional post and involuntary low employment. Graduates work and the relevant specialized degree is only about $60 \% .25 \%$ of people choose the specialty independent work mainly because of less than professional standards [2].

In this context, it has become the consensus of the academic circles at home and abroad that employment ability is one of the key factors for the success of the employment of College Students, the definition of employment ability also has a lot of discussion.

Fugate thought, employment ability is refers to the individual confirmed in its occupation period and the ability to achieve both inside and outside the organization of the occupation opportunity [3]. Brown thought, employment ability is relatively a chance to find and maintain different employment [4]. The Confederation of British industry believed that employment ability is the individual as the need to adjust to change employers or customer and qualifications or competitive ability, and the ability to release the passion and potential at 
work [5].

The domestic scholars had also discussed a lot on the definition of employment ability: Xiaoming Zhen believed that employment refers to the ability of university graduates in school through the development of knowledge learning and comprehensive quality and obtain employment can realize the ideal, to meet the needs of the society, realize the value of the power in social life [6]. Yi Wang believed that the essence of employment ability is a kind of individual ability, is the sum of all kinds of beneficial to the employment ability, and has the dynamic development tendency [7].

Although each definition of employment ability is different, there are two propositions has been generally recognized: First, college students employment ability is a comprehensive ability, is a variety of personal ability after the integration of the results; second, the employment ability has a great role and positive impact on the quality of employment [8].

Exploration of College Students' employment ability can make the individual college students more likely to find their own shortcomings and improvement, can make the government, society, school and formulate corresponding policy to improve college students' employment ability, and to help the social problem of employment of college students to solve. Therefore, college students' employment ability` ingredients have increasingly become a hot topic of concern.

The United States Department of labor proposed, the twenty-first Century employment personnel must possess five capacity and three bases, three base is the foundation, thought foundation, basic quality; The five is the ability to determine, organization, planning and distribution ability, good interpersonal skills and ability to work with others, obtain and use information ability, ability to the complicated relationship between cognition and the operation of the system, the ability to work using a variety of scientific and technological knowledge meanings[9].Peril presented employment ability should include four components: asset, development, expression and environmental [10]. Raul thought that the employment ability mainly is composed by three dimensions: personal adaptability; interaction of individual and market occupation identity [11]; Lihua Zhang suggested that, college students employment ability includes five dimensions that is namely, social ability, thinking ability, independent ability, social practice ability, and application ability [12]; Guoxue Song thought that college students employment ability by the professional skills, communication skills, personal attributes, learning ability, interpersonal skills[13]. Ting Wang, Xiangquan Ceng, Yumei Yang. The college students employment ability model made by knowledge elements, ability elements, elements of the attitude, in which knowledge is divided into professional knowledge and non professional knowledge; capacity factor into operation skills, communication and understanding skills, management skills, self-control skill and scientific thinking skills; attitude factor into occupation accomplishment, will quality and character[14], Zheng Wang, Bo Zhao, Yaojun Luo, Ying Jin, Shisong Qing et al., respectively on the college students employment ability model was constructed by different algorithms[15-19]; Xinhua Yang, Yali Tan, Linkai Wang, Yaoxiang Zhang et al. Based on the different angle discussed the college students employment ability factors[2,20-22].

However, European and American countries is the basic point of departure of the research on College Students' employment ability of mostly foreign scholars, does not match our country's reality, and although the domestic studies has a lot discussion on this question, but most of these studies are in the theory stage, lack of empirical research, and they ignores the distinction between subjects, which is equivalent to consider each factor of student's employment ability in the students employment to the same effect. At the meantime, as the starting point of this argument is based on a survey of students, schools, it also ignores the 
basic supply and demand situation in the job market; the mathematical method is often too complex to analysis the model of employment ability.

As the science and engineering graduates employment selection standard and way of working are all greatly different from other subjects' graduates, it is necessary to obtain employment ability factor of science graduates for research.

In this paper, on the basis of computer software to reduce the complexity of mathematical method, and one of the three national education bases - Hefei's employer surveys and academic experts to determine the science and engineering student' employment ability factor, to make it is available to use mathematical method to analysis employment model, and to ensure the employer's opinion to be given adequate attention. At the same time, utilizing the FAHP to data mining the data of Hefei`s colleges` science and engineering graduates employment, establish the employment ability model. This paper is structured as follows:

The first section, to the domestic and foreign research on employment ability is briefly introduced, and analysis of the research issues and the necessity, the paper structure;

The section second, the related theory and application of AHP;

The third section, the application of FAHP;

The fourth section, using the fuzzy analytic hierarchy process to establish science and engineering graduates' employment ability model and empirical evaluation of individual students;

The research steps of this paper as shown in Figure 1.

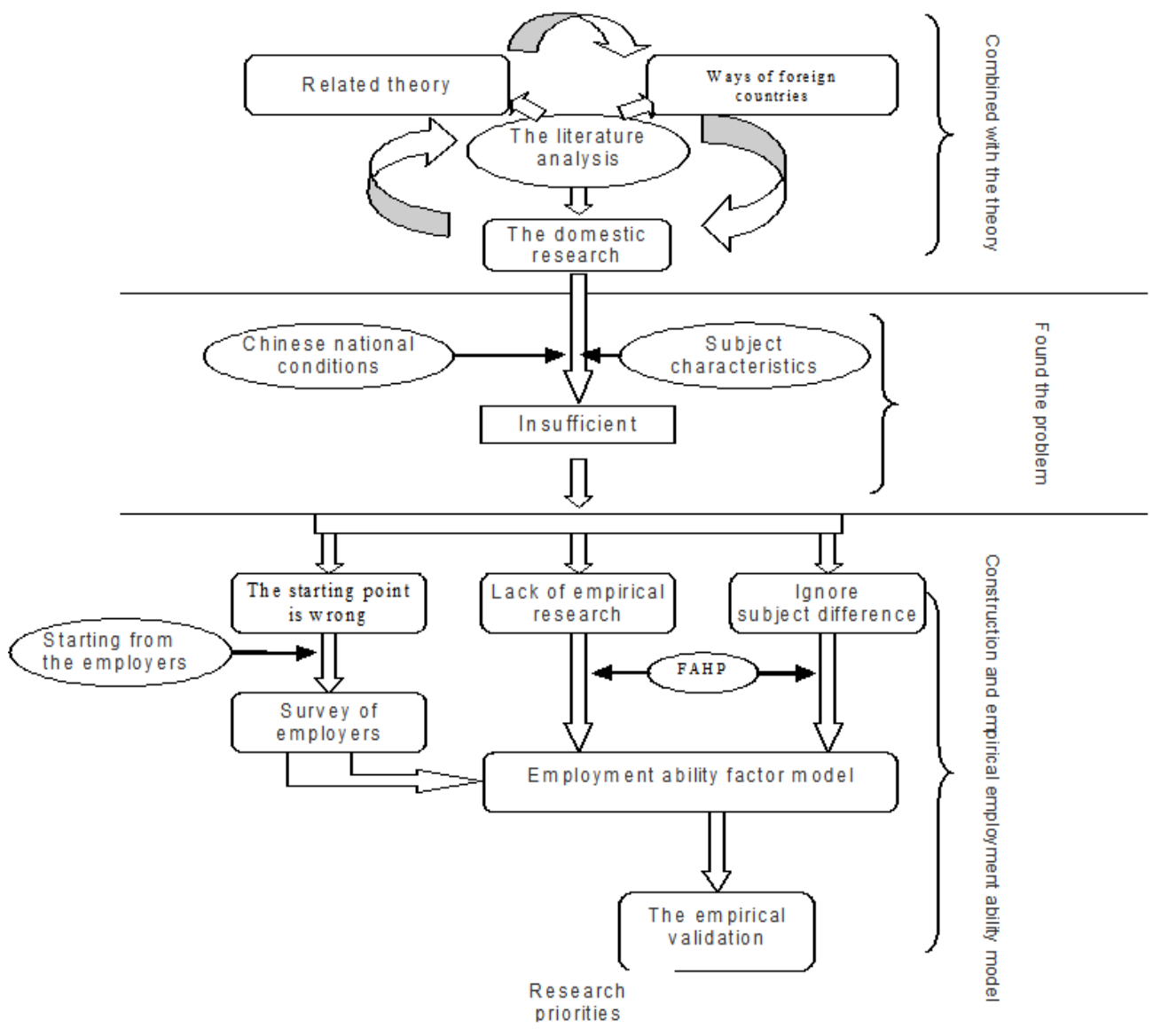

Figure 1. Research Steps 


\section{The AHP Theory}

AHP is a decision-making method that based on qualitative and quantitative analysis. It is a common method of multi objective decision. This hierarchy of decision analysis method was suggested by the United States of America Operations researcher Professor Serta from the University of Pittsburgh in the early nineteen seventies, for the United States Department of defense for research "according to each industrial sector contribution to the national welfare and the power allocation "subject. It is an application of network system theory and multi-objective comprehensive evaluation method.

The characteristics of the AHP is the using of less quantitative information to decisionmaking process of mathematical thinking, decision-making method which is more objective, multi criteria or non structure characteristic of the complex decision problems, bases on the analyzing of complex decision problems, its inherent relationship between factors and so on.

Its basic idea is, first, according to the characteristics of multi-objective decision-making problems and the general target, decomposition the problem according to levels of for the target layer, criterion layer and scheme layer three levels, constitute a hierarchy from the bottom up, The target layer is the most senior, refers to the general goal is to solve the problem, the criterion layer refers to the standard intermediate measures, while the bottom most scheme layer refers to various kinds of project scheme for the solution to the problem. And between two adjacent upper and lower elements also exist specific logical relation, thereby the elements of each level is a linear form and it has a lower elementary logic connected, so as to form a complete hierarchical structure model. For a decision problem, after an ordered structure formed by the above method, each of the upper elements, considering the logical related lower elements, and to judge these underlying factors between them on a certain of their characteristics (this paper is to estimate the importance of them). The results in the final quantitatively numbers and said in a "judgment matrix", which consists of the judgment matrix of numbers. To further determine the maximum eigenvalues and eigenvectors of the judgment matrix, so as to determine the weight of a characteristic of each element of each level of relative degree value. Then through to the level of the comprehensive and give the target layer, the total order weight scheme [23]. The advantages and disadvantages of the AHP as showed in Figure 2.

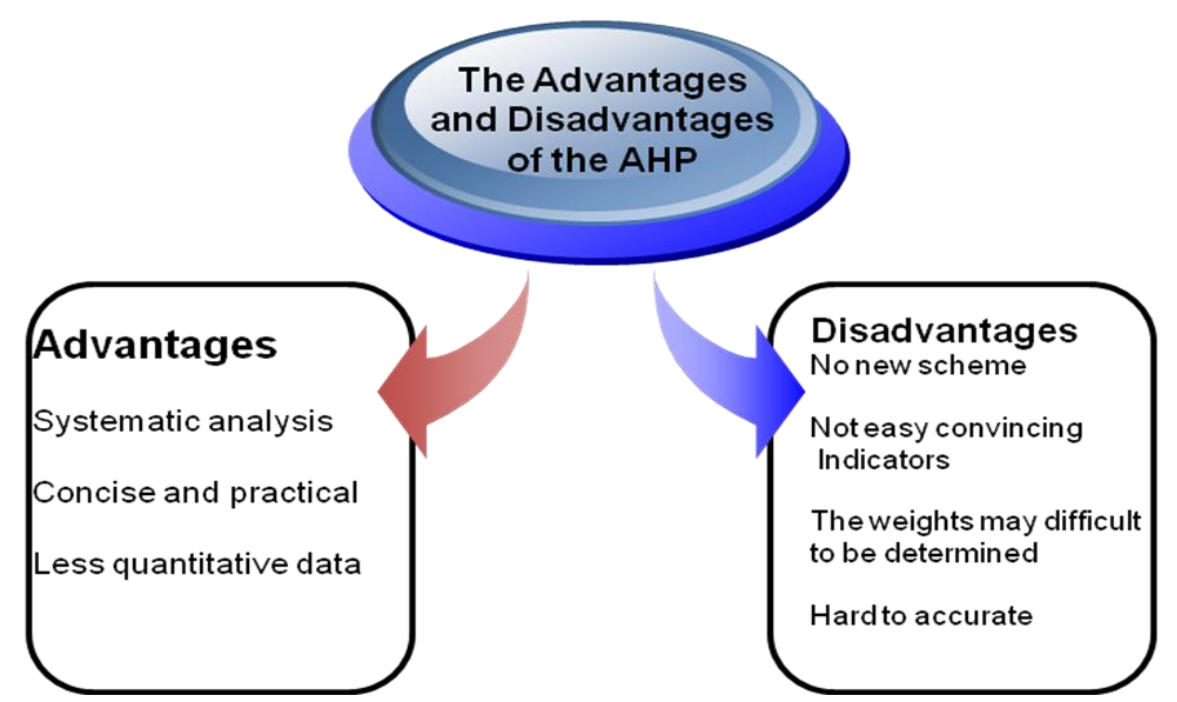

Figure 2. The Advantages and Disadvantages of the AHP 
Based on the analytic hierarchy process characteristics, make method of Delphi and AHP combined, so as to avoid the results too subjective, at the same time, the results of previous studies are modified, integration, on one hand the research relatively solid foundation, on the other hand also avoids data caused by too much calculation is too complicated.

AHP is divided into five basic steps:

The first step, constructs the hierarchical structure model:

In this paper, according to the basic principle of the analytic hierarchy process, basic employment ability factor proposed by scholars at home and abroad, through practical investigation, establishes a hierarchical structure model needed.

The second step, constructing judgment matrix:

In this paper, constructing judgment matrix is designed to represent the hierarchical structure model, the level of the elements according to the relative importance between hierarchies of an element. Assume that elements of a layer $A_{k}$ and layer $B_{1}, B_{2} \ldots B_{n}$, contact, judgment matrix is constructed as showed in Table 1.

Table 1. Judgement Matrix

\begin{tabular}{|c|c|c|c|c|c|}
\hline$A_{K}$ & $B_{1}$ & $B_{2}$ & $B_{3}$ & $\cdots \cdots$ & $B_{n}$ \\
\hline$B_{1}$ & $b_{11}$ & $b_{12}$ & $b_{13}$ & $\cdots \cdots$ & $b_{1 n}$ \\
\hline$B_{2}$ & $b_{21}$ & $b_{22}$ & $b_{23}$ & $\cdots \cdots$ & $b_{2 n}$ \\
\hline$B_{3}$ & $b_{31}$ & $b_{32}$ & $b_{33}$ & $\cdots \cdots$ & $b_{3 n}$ \\
\hline$\cdots \cdots$ & $\cdots \cdots$ & $\cdots \cdots$ & $\cdots \cdots$ & $\cdots \cdots$ & $\cdots \cdots$ \\
\hline$B_{n}$ & $b_{n 1}$ & $b_{n 2}$ & $b_{n 3}$ & $\cdots \cdots$ & $b_{n n}$ \\
\hline
\end{tabular}

$B_{i}$ on the $B_{j}$ value of $A_{k}$ is $b_{i j}$, the relative importance of, usually $1,2, \ldots \ldots$ The 9 , and their reciprocal.

$B_{i}$ and $B_{j}$ have the same importance of $b_{i j}=1$;

$B_{i}$ slightly more important than $B_{j} b_{i j}=3$;

$B_{i}$ was more important than $B_{j} b_{i j}=5$;

$B_{i} \quad B_{j}$ very important $b_{i j}=7$;

$B_{i} \quad B_{j} \quad b_{i j}=9$ is extremely important;

2, 4, 6, 8 are meant for the two adjacent judgment median.

Through the above principle can be seen, the matrix elements in the judgment are: $b_{i i}=1$, $b_{i j}=\frac{1}{b_{j i}}(\mathrm{i}, \mathrm{j}=1,2, \ldots \ldots, \mathrm{n})$, and only need to give $\frac{n(n-1)}{2}$ to determine the number. When the element of judgment matrix is: $b_{i j}=\frac{b_{i k}}{b_{j k}}(i, j, k=1,2, \cdots, n)$, said the judge has consistency. In the application of AHP is a most important point, is to keep the consistency of the judgment.

The third step, single level sequencing

According to the calculation results of the judgment matrix, a layer of an element, the level of logical elements and their relative importance weights is single level sequencing. As to the single level sequencing, need further to determine the calculation of eigenvector corresponding eigenvalues of $B$ matrix. The calculation to meet: feature vector $W$ $B W=\lambda_{\max } W$ (the normalization eigenvector), its component $W_{i}$ in the corresponding element array weights. 
In order to ensure the consistency of the judgment matrix, need to calculate the consistency index of it to test $C_{i}=\frac{\left(\lambda_{\max }-n\right)}{n-1}$ For judging the consistency of the judgment matrix is satisfactory, also has to use $R_{i}$ which means random consistency index of judgment matrix. For 1-10 order judgment matrix, $R_{i}$ values are shown in the Table 2.

Table 2. $R_{i}$ Values

\begin{tabular}{|c|c|c|c|c|c|c|c|c|c|c|}
\hline Order number & 1 & 2 & 3 & 4 & 5 & 6 & 7 & 8 & 9 & 10 \\
\hline$R_{i}$ & 0 & 0 & 0.58 & 0.96 & 1.12 & 1.24 & 1.32 & 1.41 & 1.45 & 1.49 \\
\hline
\end{tabular}

That consistency of judgment matrix is satisfied, the $C_{R}$ must meet the following conditions: $C_{R}=\frac{C_{i}}{R_{i}} \leq 0.1$, otherwise, it is needed to adjust the judgment matrix, consistency until a satisfactory.

Combining all levels at the same level of a single sort results, can be obtained for a hierarchy element, the relative importance weights of the levels of all elements of the value, namely the level of the total order. The level of absolute order is from up to down by layer by layer sequence.

The fifth step, GAHP

In the process of solving actual problems, the decision problem of a complex system is largely required by multiple decision makers (experts) and even decision-making departments to participate in the making. In this way, the judgment matrix in the process of the construction of multiple decision makers and solving their respective thus results also may be not the same, in this case, how to judge the expert can comprehensive each sort results of the elements, to reach a reasonable sort the elements of judgment, this is GAHP to answer the question, the calculation steps are as follows: first, the ranking vector of each expert, then the corresponding components of the vector in accordance with the "mean" or "average" method to obtain comprehensive ranking vector [24].

\section{The FAHP}

Fuzzy mathematics be to use mathematical tools to solve problems of fuzzy things, the creation of fuzzy mathematics to mathematics application, from the exact extended to fuzzy field, to handle the complex system problem. Fuzzy comprehensive evaluation is the use of some of the concepts of fuzzy mathematics method, provides some evaluation of the comprehensive evaluation problem of the actual. The basic idea is: in the evaluation factors, factor of the evaluation grade and weight basis, set the transformation theory of the fuzzy membership to describe, to blur the line between factors, factor, fuzzy matrix, the composite operation of multilayer, ultimately determine the evaluation object belongs to class. Specifically, the fuzzy comprehensive evaluation is based on fuzzy mathematics and fuzzy relationship synthetic principle to quantitative the factors that the boundary is not clear, not easy quantitative, and comprehensive evaluation from multiple factors. The main steps are as follows:

The first step, determines the evaluation factors and evaluation grade: 
To determine the factors according to the nature of the thing itself, Let $U=\left\{u_{1}, \cdots, u_{n}\right\}$ characterizations are evaluation of $M$ factors of the object (i.e. evaluation index), Then the $M$ factor is divided into several subsets according to some of its properties, the first sub sets are analyzed, and then analysis the whole. $V=\left\{v_{1}, \cdots, v_{n}\right\}$ characterizations of each factor are judgment (i.e., evaluation grade). Where $M$ is the number of evaluation factors; $N$ is the number of comments. Comments such as: $V=\{$ excellent, verygood, good, bad, verybad $\}=\{5,4,3,2,1\}$.

The second step, determines the weights and evaluation matrix.

Weight set: The weight denoted as $W=\left\{W_{1}, \cdots, W_{n}\right\}$. The weight of $N$ sub factors $W_{i}$, denoted as $W_{i}=\left\{W_{i 1}, \cdots, W_{i m}\right\}, i=(1, \cdots, m)$. And $\sum_{i=1}^{m} W_{i}, \sum_{j=1}^{n} W_{i j}$ are the weight expressed quantitatively factors important degree, it will directly affect the accuracy of the evaluation results, according to the experts, by the above analytic hierarchy process to determine the weight of each factor.

Determine the evaluation matrix: In many practical problems, to identify u the elements of the set membership size can be obtained by fuzzy statistical method, namely through the fuzzy statistical test, find out the statistical law.

In the actual operation of the fuzzy statistical method, a number of experts can score for each factor, the statistical $R=\left\{R_{1}, \cdots, R_{n}\right\}$. Where $R_{i}$ is the number of points and normalized, can be fuzzy judgment matrix: a level fuzzy evaluation vector factors, all fuzzy evaluation of single factor vector composed of multi factor fuzzy evaluation matrix.

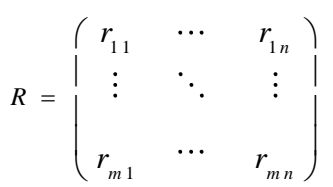

In the formula, $R_{j p}$ membership to class $P$ comment $V P$ on $U_{i j}$ in the factors of evaluation factors

The third step, the fuzzy synthesis and making decision: different lines of $R$ reflecting the membership degree of a fuzzy subset evaluation objects for each grade from the single factor of different point of view. Using the fuzzy weight vector $W$ will be different for a comprehensive, may obtain the membership degree of the evaluation object with the general point of view for each grade fuzzy subsets, namely fuzzy comprehensive evaluation result vector. Introducing a fuzzy subset of $B$, called the fuzzy rating, and also called the decision set.

$$
\begin{aligned}
& B=\left\{B_{1}, \cdots, B_{n}\right\} \\
& B=W \times R
\end{aligned}
$$

$B_{i}$ said the objects to be evaluated with comments $V_{i}$ degree. Each evaluation index, as reflected in the evaluation of the distribution characteristics of the image of judgment, the judge has more in-depth understanding, and can deal with all kinds of flexible things. If you want to choose a decision, you can choose the best $B_{i}$ the corresponding grade $V_{i}$ as a comprehensive evaluation of the results; if the evaluation level, determine the grade according to the weighted average method. This method considers all indicators contributions, is a suitable treatment measures [25]. 


\section{Establish Science and Engineering Graduate's Employment Ability Model Based on FAHP Method}

\subsection{Experimental Backgrounds}

Although research on university graduates employment ability is common, but on the exploration of science and engineering graduates`employment ability is uncommon. In fact, the research to the employment ability of graduates in science and engineering is the deepening application of employ ability theory in university education, conducive to the realization of students' individual voluntary full employment, so as to promote the students, the school, the social three aspects of harmonious development, therefore, is a very necessary work.

As everyone knows, the general form of the university graduates employment market is to pile up in excess of requirement, so if exclude students' family`s background and "relationship" factors, only consider the students by "free competition" means to achieve voluntary full employment, with the choice of people standard unit is undoubtedly play a leading role. Therefore, this paper is different from most other similar research scholars, from the employer's perspective (rather than the students point of view), constructing judgment matrix based on the literature and empirical, and then use of FAHP and Delphi method to data mining are discussed.

Again, graduates volunteered to full employment as the premise, do not consider the students employment to parents, family background and other factors.

\subsection{Determining Factors}

Through the full research on the existing literature, refining the employment ability factor, and then the employer recruitment to be interviewing and collecting interview scoring table used for the data to supplement and amendment to the college students employment ability factor, job description of representative enterprises of the technical professional level posts also had been collected and then on all these basis, collect the common requirements of employment ability and then integration of employment ability factor under the guidance of Higher Education experts. The way of determining factors as showed in Figure 3.

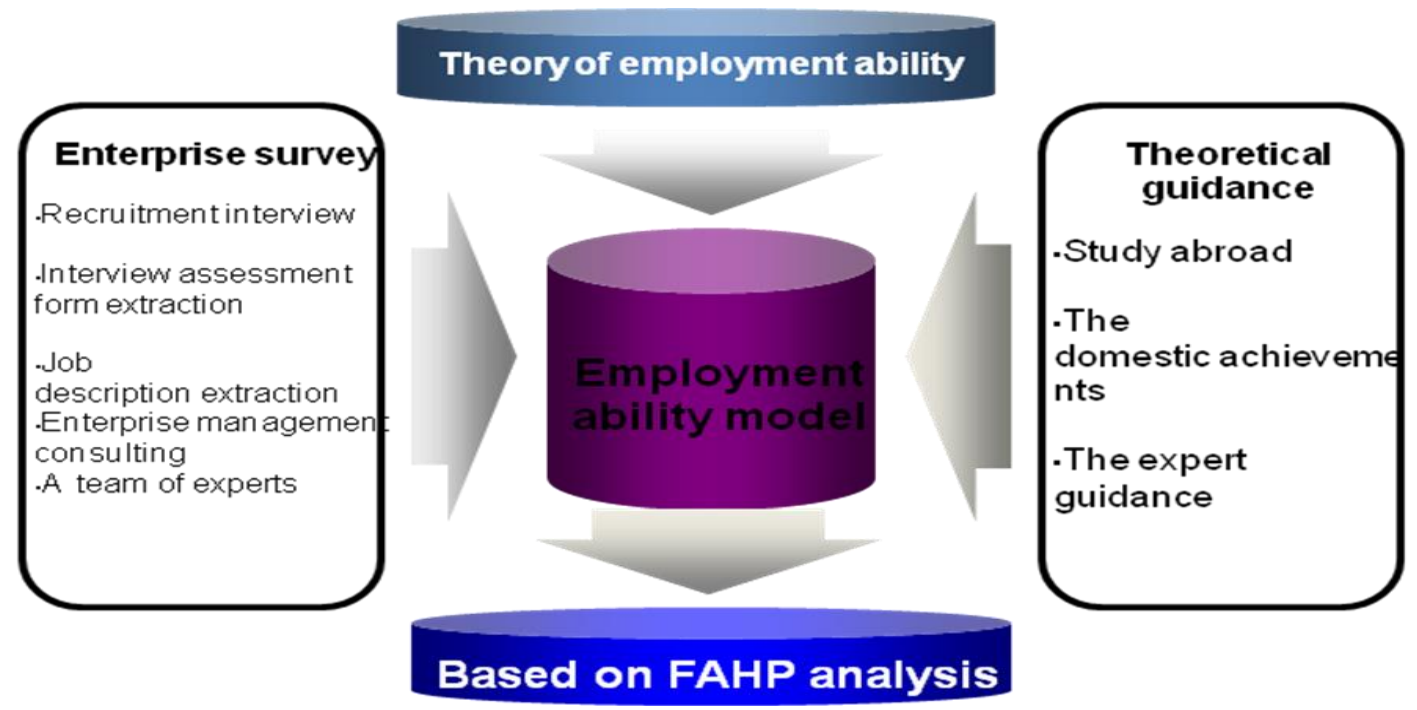

Figure 3. Determining Factors 
The university graduates employment ability factor as described in the following Table 3:

Table 3. Science and Engineering Graduates' Employment Ability Factor

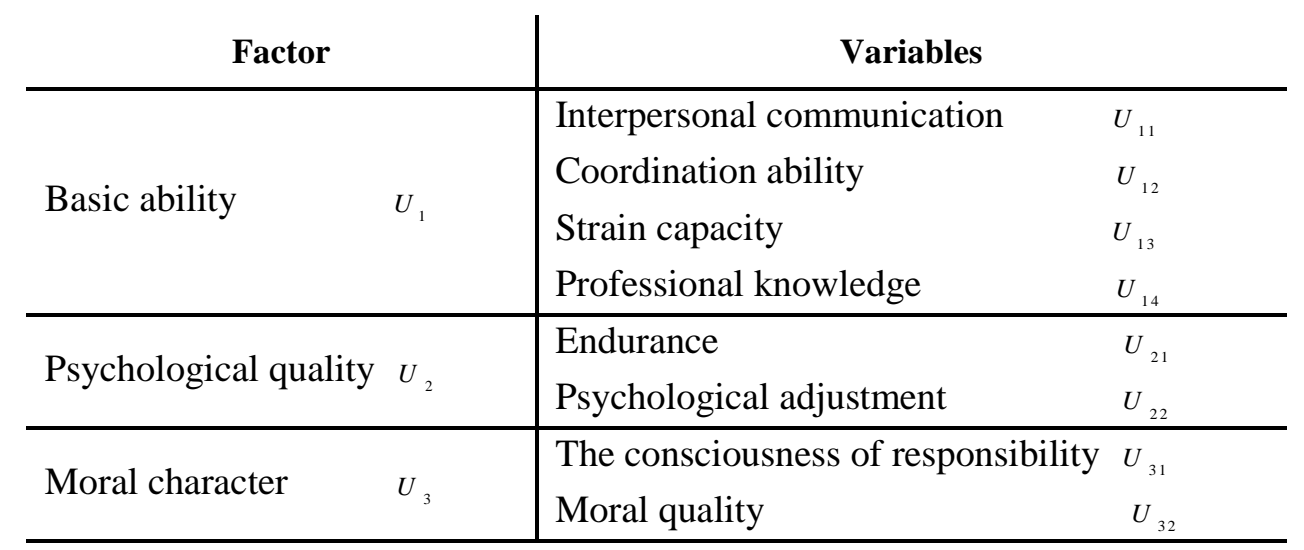

\subsection{Determining the Employment Ability Factor Weights}

A group of 10 experts from China Mobile, China Unicom, ornamented by a group of 5 representative enterprise, who are technology and responsible person or recruitment, evaluation of all the elements, structure of the two-two comparison matrix, and matrix of eigenvectors $W$ and eigenvalues $\lambda$ is obtained, and through the consistency index $C_{i}$ and the average random consistency index $R_{i}$, calculate the consistency ratio $C_{R}$ and consistency of each component, thus has been meet the eigenvectors corresponding to the judgment matrix consistency test is the weight of each index on top of the. Specific process is as follows.

To calculate the weight of $U_{1} U_{2}$ and $U_{3}$ using the AHP method, as shown in Table 4.

Table 4. The Weight of $U_{1} U_{2}$ and $U_{3}$

\begin{tabular}{|c|c|c|c|c|}
\hline & $U_{1}$ & $U_{2}$ & $U_{3}$ & Weight \\
\hline$U_{1}$ & 1 & 3 & 5 & 0.514 \\
\hline$U_{2}$ & $1 / 3$ & 1 & 3 & 0.2746 \\
\hline$U_{3}$ & $1 / 5$ & $1 / 3$ & 1 & 0.2095 \\
\hline$\lambda_{\max }=5.193 \quad C_{I}=0.038 \quad R_{I}=1.12 \quad C R=0.035<0.1 \quad$ To meet the consistency test \\
\hline
\end{tabular}

AHP method was used to calculate $U_{11}, U_{12}, U_{13}$ and $U_{14}$ weight, such as table5, similarly, can calculate the weight of $U_{21}, U_{22}, U_{31}$ and $U_{32}$ were $0.1700,0.1046,0.1321$ and 0.0774 .

Table 5. The Weight of $U_{11} U_{12} U_{13}$ and $U_{14}$

\begin{tabular}{|c|c|c|c|c|c|}
\hline & $U_{11}$ & $U_{12}$ & $U_{13}$ & $U_{14}$ & Weight \\
\hline$U_{11}$ & 1 & 5 & $1 / 7$ & $1 / 9$ & 0.084 \\
\hline$U_{12}$ & $1 / 5$ & 1 & $1 / 3$ & $1 / 5$ & 0.037 \\
\hline$U_{13}$ & 7 & 3 & 1 & $1 / 3$ & 0.1747 \\
\hline$U_{14}$ & 9 & 5 & 3 & 1 & 0.2183 \\
\hline$\lambda_{\max }=4.028$ & $C_{I}=0.095$ & $R_{I}=0.090 \quad C R=0.01<0.1 \quad$ To meet the consistency test \\
\hline
\end{tabular}


The employment ability factor model as shown in Table 6:

Table 6. The Employment Ability Factor Model

\begin{tabular}{|c|c|c|c|}
\hline Factor & $\begin{array}{c}\text { Variables } \\
\end{array}$ & & Weight \\
\hline \multirow{4}{*}{ Basic ability } & Interpersonal communication & $U_{14}$ & 0.084 \\
\hline & Coordination ability & $U_{14}$ & 0.037 \\
\hline & Strain capacity & $U_{14}$ & 0.0747 \\
\hline & Professional knowledge & $U_{14}$ & 0.4183 \\
\hline \multirow[t]{2}{*}{ Psychological quality $U_{2}$} & Endurance & $U_{14}$ & 0.17 \\
\hline & Psychological adjustment & $U_{14}$ & 0.1046 \\
\hline \multirow{2}{*}{ Moral character } & \multirow{2}{*}{\multicolumn{2}{|c|}{$\begin{array}{l}\text { The consciousness of responsibility } U_{14} \\
\text { Moral quality }\end{array}$}} & 0.0321 \\
\hline & & & 0.0774 \\
\hline
\end{tabular}

Compared with previous research results, we found that for science and engineering graduates' employment ability of professional knowledge more strictly, relatively speaking, in interpersonal communication and coordination capacity requirements such as low. Psychological quality requirements are higher than psychological stress tolerance.

\subsection{Determine the Evaluation Set and Single Factor Assessment}

The expert group continue to evaluate the student A`s employment ability factor using this model and set up evaluation set to $\{$ bad, poor, medium, good, verygood $\}=\{1,2,3,4,5\}$, the evaluation set $P=\left\{P_{1}, \cdots, P_{10}\right\}$, to get the single factor evaluation, as shown in the Table 7:

Table 7. Evaluation of Student A's Employment Capacity

\begin{tabular}{|c|c|c|c|c|c|c|c|c|}
\hline & $U_{11}$ & $U_{12}$ & $U_{13}$ & $U_{14}$ & $U_{21}$ & $U_{22}$ & $U_{31}$ & $U_{32}$ \\
\hline$P_{1}$ & 1 & 3 & 1 & 1 & 3 & 3 & 3 & 2 \\
\hline$P_{2}$ & 1 & 2 & 1 & 1 & 2 & 3 & 5 & 3 \\
\hline$P_{3}$ & 1 & 1 & 2 & 1 & 2 & 3 & 4 & 3 \\
\hline$P_{4}$ & 2 & 2 & 1 & 2 & 1 & 2 & 3 & 2 \\
\hline$P_{5}$ & 1 & 2 & 1 & 1 & 1 & 2 & 4 & 4 \\
\hline$P_{6}$ & 1 & 2 & 1 & 1 & 2 & 3 & 5 & 2 \\
\hline$P_{7}$ & 2 & 2 & 1 & 2 & 2 & 2 & 4 & 3 \\
\hline$P_{8}$ & 2 & 3 & 2 & 1 & 1 & 3 & 5 & 3 \\
\hline$P_{9}$ & 1 & 1 & 1 & 1 & 3 & 2 & 3 & 2 \\
\hline$P_{10}$ & 2 & 3 & 1 & 2 & 3 & 3 & 4 & 4 \\
\hline
\end{tabular}

From the table to the fuzzy evaluation matrix is as follows: 


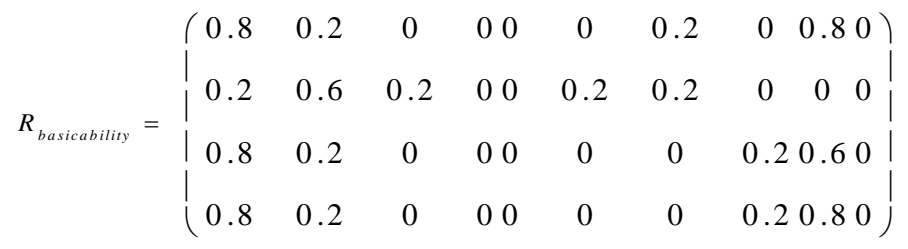

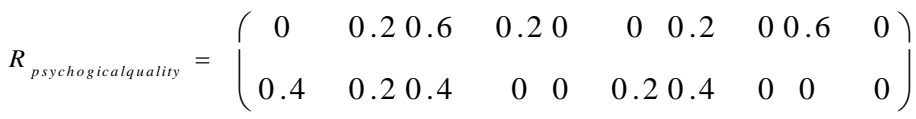

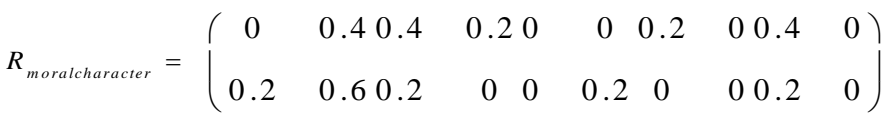

Combining with each factor variable employment ability factor model and the weight, the availability of a fuzzy comprehensive evaluation results:

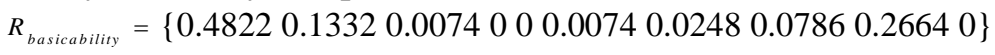

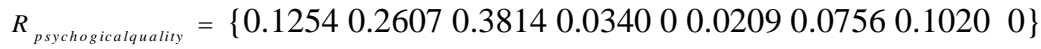

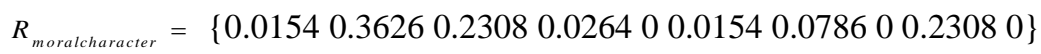

Then the level two fuzzy evaluation, the final evaluation result is: the student's employment ability is poor, poor, medium, good and very good degree of membership are respectively $36.9 \%, 29.4 \%, 27.1 \%, 5.5 \%$ and $1.1 \%$, the $s$ value is 2.045 , so the students employment ability for medium. By observing the whole evaluation process can be learned, the student A to improve his employment ability, a pressing matter of the moment is to promote the professional knowledge.

\section{Conclusion}

Firstly, in this study, the employer's point of view, different from the previous research used students or school as the point of view, followed, by FAHP, the science and engineering graduates employment ability factor model had established, and learned that for science and engineering graduates' employment ability of professional knowledge more strictly, relatively speaking, in interpersonal communication and coordination capacity requirements is lower. Psychological quality requirements are higher than psychological stress tolerance. At last take A student for example of the evaluation, not only get the student's employment ability, but also knew the key aspects to be improved through the process of evaluation. Studying the process has the role of promoting the theory of employment ability to be used in the university students' employment education.

However, this study also has shortcomings: first of all because of the fuzzy AHP method, the research methods are limited, there are subjective factors in the result; secondly, because the number of experts is scarcity and there are too many college graduates, the setting up expert team to evaluate student is very restrictive in practice, finally, this paper; specific science and engineering graduates of employment ability factor model, ignoring the characteristics of each professional science and engineering. These issues will be further deepened in the future research. 


\section{References}

[1] S. Liao and D. Xiong, "The competency is the core of the college students employment model construct taking competence as the core", [J], Fujian forum Humanities and Social Sciences, no. 6, (2013).

[2] Y. Gao, "As the core to promote the employment competitiveness of the occupation college student employment guidance system", [J], China Adult Education,( 2013).

[3] M. Fugete, A. J. Kinicki and B. E. Ashforth, "Employability: A Psycho-social construct", Its Dimensions and Applications", [J], Journal of Vocational Behavior, no. 1(2004).

[4] L. D. P. Pool and Sewell, "The Key to Employability: Developing a Practical Model of Graduate Employability", [J], Education and Training, vol. 49, no. 4, (2007).

[5] "In Search of Employability", [R], A Response by NIACE to the CBI Discussion Document, (1998).

[6] X. Zhen, "The "employability" theory" ,[J], Journal of China Youth University for Political Science, , no. 3, (2002).

[7] Y. Wang, "Employment Ability: an important aspect to promote the employment [J] Research on the development of Education, no. 4, (2005).

[8] Z. Guo, B. I. J. M. Van and O. Den, "No boundary occupation career era employment ability: a new psychological contract", [J], Psychological Science, no. 2, (2006).

[9] U.S Department of Labor. What Work Requires of School: A SCANS Report of America;

[10] J. Hillage and E. Pollard, "Employability: Developing a Framework for Policy Analysis", [R], London: Department for Education and Employment, (1998).

[11] K. S. Law, C. Wong and W. H. Moldy, "Toward Taxonomy of Multidimensional Constructs", [J], Academy of Management Review, no. 4, (1998).

[12] L. Zhang and S. Liu, "Experimental study of college students employment ability structure and development characteristics", [J], Nautical education research, no. 1, (2005).

[13] G. Song, "Study on the structure of College Students", occupation ability dimension, based on the employability perspective, [J], China Soft Science, no. 12, (2008).

[14] T. Wang and X. Zeng, "To improve the employment ability to solve problem of the structural unemployment of College Students", [J], Population and economic, no. 3, (2011).

[15] Z. Wang, "Employment competitiveness of poor students in colleges and universities from the perspective of the SWOT analysis theory", [J], Forward position, no. 9, (2013).

[16] B. Zhao, "Construction and reasoning of Bayesian network model of the student employment", [J], Journal of Yunnan Nationalities University (Natural Sciences Edition), no. 4, (2008).

[17] Y. Luo, "Using the ID3 algorithm to create employment analysis model", [J] Internet fortune, no. 6, (2009).

[18] Y. Jin, "Application of decision tree algorithm in the employment of College Students", [R], Hefei University of Technology, (2009).

[19] S. Qing, "College Students' employment decision factors analysis based on multi model method", [J], Population \& Economics, no. 1, (2009).

[20] X. Yang, "Study on the employment ability structure model of post-90s College Students", [J], Population \& Economics, no. 2, (2012).

[21] Y. Tan, "College graduates employment ability structure and fit research and employers demand. [J] Research on High Engineering Education, 2011, (2);

[22] Yaoxiang Zhang. Study on the employment of college graduates quality evaluation of based on three party satisfaction, [J] 2013, (5);

[23] The spatial framework for weight sensitivity analysis in AHP-based multi-criteria decision making. [J] Environmental Modeling \& Software, 48(2013), 129-140;

[24] Duanyong Liu. Research of Jinwei company technical staff occupation career channel based on post analysis. [R] Hefei University of Technology, 2011;

[25] Lina Zhang. Application of AHP and fuzzy comprehensive evaluation method in the evaluation of eco industrial park. [R] Hefei University of Technology, 2010; 


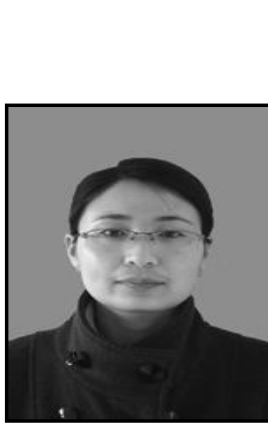

\begin{abstract}
Authors
Liwei Gu, she received her bachelor's degree of education in Hebei Normal University Shijiazhuang, Hebei, (2002) and master's degree of Software Engineering in Beijing University of Technology, Beijing, (2010), Now she is a lecturer in Hebei Normal University of Science \& Technology, Qinhuangdao, Hebei. Her major fields of study are education technology, distance learning, software engineering and education technology.
\end{abstract}

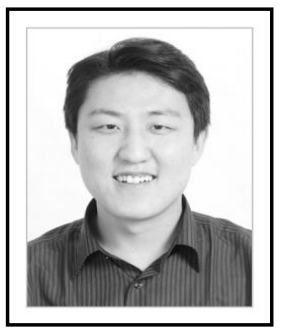

Yubin Wang, he received his bachelor's degree of engineering in Yanshan University, Qinhuangdao, Hebei. (2000) and master's degree of engineering in Yanshan University (2009), Now he is a lecturer in Hebei Normal University of Science \& Technology, Qinhuangdao, Hebei. His major fields of study are computer network technology.

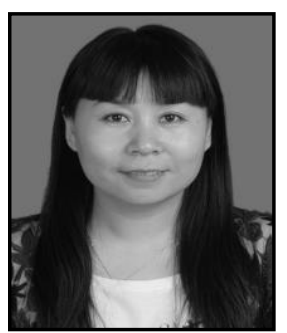

Yuhong Zhang, she received her bachelor's degree of education in Hebei Normal University of Science \& Technology, Qinhuangdao, Hebei. (2001) and master's degree of education in Hebei Normal University, Baoding, Hebei. (2007), Now she is a lecturer in Hebei Normal University of Science \& Technology, Qinhuangdao, Hebei. Her major fields of study are education technology, vocational education, and information education. 
International Journal of u-and e-Services, Science and Technology Vol.7, No.4 (2014) 